\title{
Evaluation of Training Program for New Nurses to Enhance Caring Behavior
}

\author{
Yaowaret Kanmalia, Arun Suikraduangb
}

\begin{abstract}
This research was aimed to evaluate the training program enhancing caring behaviors of new nurses by Kirkpatrick's four level for evaluation model: reaction, learning, behavior, and result of the program. The participants were new nurses, preceptors of new nurses, administrators, patients and members of the patients' family cared by new nurses. The research instruments were: (1) five questionnaires toward program suitability, knowledge, attitude, caring expression, and result to organization. The mean, standard deviation and dependent sample t-test were used for data analysis; (2) guidelines for focus group discussion and semi-structural questionnaire analyzed by content analysis. The study revealed that: (1) the mean of suitability was at the very high level $(\bar{X}=4.49$, SD. $=.30)$; (2) the knowledge and attitude after training were significantly higher than before training at .000 level, $(t=-21.65, p=.000$ and $t=-19.30, p=.000)$; (3) caring behavior after training was significantly higher than before training at the .000 level; and (4) the result of the program was at the high level $(\overline{\mathrm{X}}=4.25$, SD. $=.17$ ), related to the result of semi-structured interview and focus group discussion. These evaluation research finding suggested that administrators can use for improving the preparation of any project and apply to evaluate other training programs, developing human resource system.
\end{abstract}

\section{Keywords}

Training program evaluation, caring behavior, new nurse

Nursing is a profession about health care. Nurse's roles include promotion, prevention, relief of distress and rehabilitation (Ellis and Hartley 1998: 316). Nurses have to care the patient's body and mind (Nursing Council 2000). The three components of nursing practice are the science of nursing, art of nursing, and aesthetics in nursing (Tantiphalacheewa 1997: 14-16). Nurses need to learn about the science of nursing and science related to nursing, then apply these to nursing care suitably by using important skills such as communication regard and caring that are part of the art of nursing (Tongprateep 2005: 11).

Caring behavior is important for nursing professional training, obtained in the practicum and professional obligations to the society (Leininger 1988;
Nujareornkul 2001: 135), because caring behavior is concerned with the worth of humans and transpersonal care. Moreover, the conscious that all nurses have to always encourage themselves with the bottom of their hearts are love, kindness, and attention (Yusawat 1996: 26; Morse et al. 1990: 1-2; Mayeroff 1977: 368). While, the characteristics of duty in nursing

\footnotetext{
aKalasin Hospital, Thailand

bRajabhat Maha Sarakham University, Thailand

Correspondent Author:

Yaowaret Kanmali, Orthopedic Department, Kalasin Hospital, 283 Kalasin Street, Kalasin sub-district, Muang district, Kalasin, Thailand, 46000

E-mail: k.yaowaret@hotmail.com
} 
professional are from the serious environment and not pleasant at all times that cause nurses stressful, such as caring the patient all time, especially caring for critical ill patients, the end of a patient's life, nearly death patient and death patient. Moreover, the nursing profession characteristic is the shift on duty and always expected by patients and patient's family not to make any mistakes when giving care (Taweelap 1991: 1). These factors affect caring behavior.

Especially, new nurses after graduating are expected by patients, patient's family, health teams and administrators to have perfect knowledge, skills, morality, ethics, responsibility, and dependence of the society (Chitpradit, Sintu, and Puttanupol 2004: 10). While, the new nurses have some conflicts between professional and organizational goals such as the professional goal's focusing on caring for individual patients but organizational goals focusing on work efficiency including regulations of the organization (Ibrahim 1992: 170-175; Laar, Edward, and Easton 2007: 421). These factors affect caring behaviors of new nurses and conform to the research's findings from former nurse students that when they enter, they showed self-sacrifice, sensitivity, and kindness, but when they graduate, they are not sensitive, not caring, and not care for patient's needs (Sirili 2008: 10-12). Additionally, the research findings that caring behaviors mean scores of new nurses in Kalasin Hospital by self-perception, register's nurse perception and patient's perception were at the moderate level and conforms to focus group discussions that new nurses have uncaring behavior (Kanmali 2012: 24-35).

The training program can develop the human capital to collect the most valuable intellectual capital mean to help new nurses in their duty (Samittikai 2013: 2; Sriyanluk 2002: 203-209), because it is a systemic of learning process management to increase knowledge, skill, ability, and attitude for effects to higher work efficiency and the project setting by organization to help personnel getting higher working attribute (Goldstein and Ford 2002: 3-4; Kanmali and Suikraduang 2013: 633-638). However, the training program needs to be evaluated. Thus, the four levels of Donald L. Kirkpatrick's training evaluation model were used for evaluating the training program of new nurses in order to enhance caring behavior (Kirkpatrick 1975: 345).

\section{LITERATURE REVIEWED}

Three purposes of personnel training program are to enhance individual self-awareness, increase individual job skill, and increase individual motivation (Wexley and Latham 2002: 224-226). The question needs to be answer of evaluation is whether the training program evaluation makes personnel change or not. The change be happened is the result from training program or not and these changes can happen in other participants or not (Samittikai 2013: 294-295). The training program evaluation is the judgment or value which is used for considering the properness, worthiness, or achievement from a project after the comparison of the result with project goals, objectives, or criteria (Moers 1982: 198-203). The training program evaluation can indicate the outcomes of the program brought to the organization, and can also show whether the program will be organized in the same old way, or not, or even lead to the judgment if the program should be further organized. Moreover, it can help provide data for developing the better program. The employment of Donald L. Kirkpatrick's four level for evaluation model (Kirkpatrick 1975: 345-390; Watkins et al. 1998: 123-124; Kaufman 1996: 218-229; Kaufman 2000: 345-360) can lead to the answers as the followings.

(1) Reaction evaluation is aimed to show opinions of participants toward the training program such as what they get from the training program, the congruence of training curriculum, instructional design, and climates;

(2) Learning evaluation is aimed to inform what 
the participants received from the training program, the change of knowledge and/or skills and the change of attitude. This evaluation occurs during the training in the form of either a knowledge demonstration or test;

(3) Behavior evaluation is aimed to show the behavior after the training program turns to the proper way or transfer of knowledge, skills, and/or attitudes from classroom to the job. This evaluation occurs 3-6 months post training while the trainee is performing the job. Evaluation usually occurs through observation;

(4) Result to organization evaluation is aimed to eventually display the advantages after the program. This evaluation is the final results that occurred because of attendance and participation in a training program.

\section{MATERIALS AND METHODS}

This study was an evaluation research (Worakham 2012: 23) that evaluated the training program for new nurses to enhance caring behaviors by using Donald L. Kirkpatrick's four levels for evaluation model (Kirkpatrick 1975: 345-390). The research included quantitative and qualitative methodology in order to study: (1) reaction evaluation of new nurses indicating what they thought and felt about the training program properness; (2) learning evaluation showing the increase of knowledge and attitude; (3) behavior evaluation telling the extent of caring behavior and capability improvement and implementation/application; and (4) results to organization evaluation displaying the advantage of the organization affecting from the training program participants. The purposive participants were 30 registered new nurses of Kalasin Hospital, 30 preceptors of new nurses, seven administrators in Kalasin Hospital, seven patients admitted to the in-patient department of Kalasin Hospital, and seven members of the patients' families care by new nurses at least three days continuously. The research instruments were: (1) five questionnaires toward program suitability, knowledge, attitude, caring expression, and result from the training program. The content validity of the training program for new nurses to enhance caring behavior, attitude to caring, caring expression and result to from the program were collected by the questionnaires. To choose the valid question items, index of objective congruence (IOC) must be more than .50 . The content reliability value had been tested by Cronbrach alpha coefficient which was at .92, .76, .60, and .82. The content reliability was tested by using item difficulty which was at .4-.6, the item total correlation $\mathrm{r}_{\mathrm{xy}}$ was at .35 , and Kuder-Richardson Formula was at .96; and (2) three guidelines for focus group discussion and a semi-structural questionnaire that the researcher developed by content synthesis about caring and evaluation from the literature and research following as guideline for focus group discussion about training program suitability, attitude evaluation to caring, caring behavior expression evaluation, results from the training program, and a semi-structural questionnaire about results from the training program. The data from the training program properness and result from the program evaluation was analyzed by mean, standard deviation, knowledge and attitude evaluation were analyzed by mean, standard deviation, and dependent sample t-test and caring expression evaluation adding content analysis. The data from training program properness, attitude to caring, caring behavior expression and results from the training program collected from the focus group discussion and semi-structural interview was analyzed by content analysis (Baramee 2012: 56).

\section{RESULTS}

(1) Reaction evaluation of new nurses indicated what they thought and felt about the training program properness at once post-training as shown in Table 1. 
Table 1. Training Program Properness Evaluation $(\mathrm{N}=30)$

\begin{tabular}{llll}
\hline Item & $\overline{\mathrm{X}}$ & SD. & Level \\
\hline Content and activity/Experience & 4.68 & .48 & Very high \\
Teaching method & 4.63 & .42 & Very high \\
Duration & 4.65 & .48 & Very high \\
Instruction media & 4.70 & .46 & Very high \\
Document & 3.52 & .46 & High \\
Lecturer & 4.62 & .49 & Very high \\
Total & 4.49 & .30 & Very high \\
\hline
\end{tabular}

The training program properness from the focus group discussion participated with 30 new nurses revealed that good teaching methods were the verbalized factors toward better learning which requires as the followings: (a) acquaintance between lecturer and learner; (b) creating the learning environment by the lecturer; (c) activities should enhance among learners; (d) learners' self-preparing before class or activities helped them feel confident and ready to learn; (e) learning objective provision before each lesson; (f) a variety of instructions with teaching aids interested learners; and (g) the properness of light and temperature in classroom. However, public relations of the training program and staff arrangement to facilitate registration, information, document distribution should be considered;

(2) Learning evaluation which comprised knowledge in caring and attitude toward caring of new nurse toward pre-training and at once post-training was shown in Table 2.

Attitude toward caring of the 30 new nurses in three dimensions from focus group discussion revealed that: (a) passion of nursing profession as example the wording "I had never liked nursing profession but now I love it and I want to be a good nurse... ”, “...Today I am proud to be a nurse because a nurse is an angel... ”, “...Only patient's smile make me be happy... ", "The identity which is value of nursing professional depend on caring expression" and "I would like my sister to be a nurse, too"; (b) the attention to care patients with their mind, for example, "...from now I would do the best for my patients...", "I will devote my time for my patients", "caring... I can do it", "I will care the patient as my cousin", and “...I promise to care my patients with my mind... "; and (c) the role model, for example, "I would be a role model of nurses and nurse students", "from now I will show everyone I am a good nurse", "I believe a nurse student can be a good nurse if she has an ideal nurse so I would be that one" and "Nurses have to care both the patient's body and mind not to any one thing.... I will be model of this expression";

(3) Caring behavior evaluation from caring behavior expression from new pre-training nurses and three month post-training nurses evaluated by their preceptor of new nurses, patients admitted to the in-patient department and seven members of the patients' families was shown in Table 3.

The results from the focus group discussion contained two groups: (a) thirty preceptors of new nurses; and (b) seven patients admitted to the in-patient department of Kalasin Hospital and seven members of the patients' families about caring behavior expression of new nurse conform six caring behavior dimensions as the followings: (a) kindness, for example, the willing to care patients, the sympathy with and understand the patient's distress, the talk or touch with patients, the comfort and gentleness nursing gave and concerned with patient's needs and the stress relief; (b) the understanding and respect to 
Table 2. Knowledge and Attitude Evaluation ( $\mathrm{N}=30)$

\begin{tabular}{llllllll}
\hline \multirow{2}{*}{ Item } & \multicolumn{3}{c}{ Pre-training } & \multicolumn{2}{c}{ At once post-training } & \multirow{2}{*}{$\mathrm{t}$} & $\mathrm{S}$ \\
\cline { 2 - 8 } & $\overline{\mathrm{X}}$ & $\mathrm{SD}$ & $\overline{\mathrm{X}}$ & $\mathrm{SD}$. & & & \\
\hline Knowledge in caring & 27.83 & 2.72 & 36.03 & 1.56 & 29 & -21.65 & .000 \\
Attitude toward caring & 104.70 & 10.06 & 133.93 & 5.22 & 29 & -19.30 & .000 \\
\hline
\end{tabular}

Table 3. Caring Behavior Evaluation $(\mathrm{N}=30)$

\begin{tabular}{|c|c|c|c|c|c|c|c|}
\hline \multirow{2}{*}{ Item } & \multicolumn{3}{|c|}{ Pre-training } & $\begin{array}{l}\text { Three month } \\
\text { post-training }\end{array}$ & \multirow[t]{2}{*}{ - df } & \multirow[t]{2}{*}{$\mathrm{t}$} & \multirow[t]{2}{*}{ Sig } \\
\hline & $\mathrm{X}$ & SD. & $\mathrm{X}$ & SD. & & & \\
\hline Kindness & 3.13 & .28 & 4.53 & .23 & 29 & 30.44 & .000 \\
\hline $\begin{array}{l}\text { The understanding worth and } \\
\text { showing respect }\end{array}$ & 3.35 & .20 & 4.75 & .18 & 29 & 35.48 & .000 \\
\hline Professional relationship & 3.28 & .16 & 4.69 & .18 & 29 & 46.94 & .000 \\
\hline Professional competency & 3.02 & .26 & 4.55 & .19 & 29 & 38.35 & .000 \\
\hline Professional ethics & 3.21 & .20 & 4.78 & .16 & 29 & 37.15 & .000 \\
\hline Holistic care & 3.15 & .21 & 4.65 & .14 & 29 & 42.13 & .000 \\
\hline Total & 3.19 & .09 & 4.67 & .12 & 29 & 62.44 & .000 \\
\hline
\end{tabular}

patients, for example, the behavior of speaking by using gentle and polite words, giving care to critical and emergency patients, saying something to let the patient before providing care, saying "sorry" when above the patient's head or body, touched with unexpected objects, understanding each individual difference and not to get angry with or blame the patients, respect the patient's privacy, such as not to expose the patient, not show adverse behavior, listen to the patient's opinion; (c) professional relationship, for example, the behavior of greeting and talking to patients with gentle words, use easy language in conversation, making eye contact and smile when talking and caring for the patients, listening to patients, asking patients about signs, letting patients talk, asking and telling about feelings, touching patients when needed, being with the patient all the time when in pain, distress, or loss; (d) professional competency, for example, the behavior of teaching about self-care until understanding, always giving information about progression of the disease and plan of caring, helping patients to do activity, helping patient problem solving which in relation to the illness, showing good skills as well as being agile while doing it, always telling the reasons for the care before doing it, supporting by talking with the patient while caring, advising the patient about self-care, focusing on safety in care, always being present for monitoring and evaluation and notify the nursing team or health professionals to help the patient; (e) professional ethics, for example, the behavior help suddenly when patient requests it, being conscious, cautious, on time, responsible, honest, active and ready to care at all times, being willing to help the patient, keeping the patient's secrets, giving time for the patient, controlling their own emotions, waiting if the patient is not ready, and having a good personality; and (f) holistic care, for example, the behavior of letting patient and family to talk about their feelings and needs, taking care of the patient both physical and mental care, letting patients and family participate in carewith their beliefs, giving some time for the family to visit the patient, letting the patient and family do something follow their believe but not oppose to treatment, letting patients participate 
with other patients that have the same or similar illnesses, not to insult religious beliefs or culture that are different and hypersensitivity response;

(4) Results to organization evaluation which the effects on the organization resulted from new nurses and administrators at three month post-training were shown in Table 4.

Results of the training program from seven administrators in Kalasin Hospital which collected from semi-structured interview of caring behaviors: (a) the good effect of the hospital image, for example, when someone said that "Currently, the patients realize the right of receiving more and more attention from a nurse, if a nurse expresses uncaring behavior, she must be in trouble" and "After this training program, I see the unity among my new nurses. They are smart. Exactly their nursing service will make stake holders satisfied"; (b) caring behavior affecting the enhancement of nursing quality, for example, when someone said that "Caring is an integrated science and art of nursing shown by the behavior, so a new nurse with caring in her mind would be a perfect nurse. That is the most important in nursing profession because she would not make anymistakes" and "A nurse with caring mind is the best nurse who has the great achievement and quality of nursing indicators"; and (c) caring behavior enhance identities organizational in the humanized care dimension, for example, "The continuity and consistency of caring behavior indicate good organizational culture" and "Caring behavior indicate the growth of the organization”.

However, the results from the focus group discussion of 30 new nurses participated in training program revealed that: (a) it helped the organization improve human resource management, for example, when someone said "This can identify, understand, and generate personal development according to needs and wishes, in terms of: skills, knowledge, experience, and attitude such as personal well-being, emotional maturity, mood, mind-set, any other suitable term meaning mental approach, which new nurses will respond to", "This can identify and obtain effective learning and development that suits my preferred style and circumstances", "It helped me to assess and evaluate my development because I can make it clear and very easy to understand others in the organization should realize my capabilities" and "This can provide tools and systems to encourage and facilitate my personal development"; and (b) supporting job system, for examples, when someone said that "It ensured that systems and activities that we have can keep all staff understand the hospital plans, performance, etc.” and "It helped me ensure the developmental needs of my staff that need to be identified and supported".

\section{CONCLUSIONS}

The study revealed that:

(1) The mean of suitability of the training program was at the very high level $(\overline{\mathrm{x}}=4.49, \mathrm{SD} .=.30)$, related to the results by focus group discussion shown the training program was good teaching methods that verbalized factors toward better learning which requires as: (a) acquaintance between lecturer and learner; (b) creating the learning environment by the lecturer: (c) activities should enhance among learners; (d) learners' self-preparing before class or activities helped them feel confident and ready to learn; (e) learning objective provision before each lesson; (f) a variety of instructions with teaching aids interested learners; and (g) the properness of light and temperature in classroom;

(2) the new nurses' caring knowledge and attitude after training were significantly higher than before training program at the .000 level $(\mathrm{t}=-21.65, \mathrm{p}=.000$ and $\mathrm{t}=-19.30, \mathrm{p}=.000$ ), related to the results by focus group discussion shown in three dimensions from focus group discussion as: (a) passion of nursing profession; (b) the attention to care patients with their mind; and (c) the role model;

(3) The new nurses' caring behavior after training 
Table 4. Results to Organization Evaluation $(\mathrm{N}=30)$

\begin{tabular}{llll}
\hline Result to organization & $\overline{\mathrm{X}}$ & SD. & Level \\
\hline Complacency of organization stake holder & 4.60 & .22 & Very high \\
Strategy & 4.18 & .30 & High \\
Process & 3.98 & .24 & High \\
Ability & 4.02 & .33 & High \\
Benefits & 4.43 & .28 & High \\
Total & 4.25 & .17 & High \\
\hline
\end{tabular}

was significantly higher than before using the training program at the .000 level, related to the results by focus group discussion that the new nurses shown the six dimensions of caring behavior as kindness, the understanding and respect to patients, professional relationship, professional competency, professional ethics and holistic care;

(4) The mean of result of the program was at the high level $(\overline{\mathrm{X}}=4.25$, SD. $=.17)$, related to the results by semi-structured interview and focus group discussion shown the good effect of the hospital image, caring behavior enhance identities organizational in humanized care dimension, caring behavior affecting the enhancement of nursing quality and helping the organization improve human resource management and supporting job system. These evaluation research finding suggested that administrators can use for improving the preparation of any project and apply to evaluate other training programs, developing human resource system, and planning for nursing care system.

\section{References}

Baramee, J. 2012. Statistics for Medical Research and Data Analysis Using SPSS. 2nd ed. Chonburi: Bangsean-Kanpimp.

Chitpradit, K., S. Sintu, and S. Puttanupol. 2004. Problem in Practice of Nursing Graduated: Personality, Self-Esteem and Stress. Bangkok: Srinakharintharawirot University.

Ellis, J. R. and C. L. Hartley. 1998. Nursing in Today's World: Challenges, Issues, and Trend. 6th ed. Philadelphia:
Lippincott-Raven.

Goldstein, I. L. and J. K. Ford. 2002. Training in Organization: Needs Assessment, Development and Evaluation. 4th ed. Pacific Grove, CA: Brooks/Cole.

Ibrahim, F. 1992. The Content in Nursing Professional. Bangkok: Mahidol University.

Kanmali, Y. 2012. "A Study of State and Problem in Caring Behavior of New Register Nurse in Kalasin Hospital.” Environment Studying Special 8:24-35.

Kanmali, Y. and A. Suikraduang. 2013. "Analysis and Synthesis Concept of Caring in Nursing Professional." Sociology Study 3(8):633-638.

Kaufman, R. 1996. Strategic Thinking: A Guide to Identifying and Solving Problems. Arlington, VA. \& Washington, D.C. Jointly published by the American Society for Training \& Development and the International Society for Performance Improvement.

- 2000. Mega Planning: Practical Tools for Organizational Success. Thousand Oaks, CA: Sage Publications.

Kirkpatrick, D. L. 1975. Techniques for Evaluating, Training Program. San Francisco: American Society for Training and Development.

Laar, D. V., J. A. Edward, and S. Easton. 2007. "The Work Related Quality of Life Scale for Healthcare Worker." Journal of Advanced Nursing 60(3):325-333.

Leininger, M. M. 1988. Caring an Essential Human Need: Proceeding of the Three National Caring Conferences. Detroit: Wayne State University.

Mayeroff, M. 1977. On Caring. New York: Harper \& Row.

Moers, D. R. 1982. Guideline for Training Evaluation. Bangkok: The Civil Service Training Institute.

Morse, J., S. M. Solberg, W. L. Neander, J. L. Bottorff, and J. L. Johnson. 1990. "Concepts of Caring and Caring as a Concept.” Advances in Nursing Science 13(1):1-14.

Nujareornkul, S. 2001. Nursing: Science of Practice. Bangkok: RamatibdeeMahidol University.

Nursing Council. 2000. The Ethic in Nursing Professional. Bangkok: Nursing Council. 
Samittikai, C. 2013. The Personnel Training in Organization. 8th ed. Bangkok: Chulalongkorn Printing House.

Sirili, S. 2008. Ethical for Nurse. Bangkok: Chulalongkorn Printing House.

Sriyanluk, N. 2002. Nursing Administration. Bangkok: Prachumchang.

Tantiphalacheewa, K. 1997. "Content of Nursing." Alumni Nurse Association (Ministry of Public Health) 8(1):14-16.

Taweelap, W. 1991. Nursing Supervisor. Bangkok: Rungreungkanpim.

Tongprateep, T. 2005. Spirit: A Dimension of Nurse. Bankok: Boonsiri Printing.

Watkins, R., D. Leigh, R. Foshay, and R. Kaufman. 1998. "Kirkpatrick Plus: Evaluation and Continuous Improvement With a Community Focus.” Educational Technology Research \& Development 46(4):90-96.

Wexley, K. N. and G. P. Latham. 2002. Developing and Training Human Resources in Organization. 3rd ed. Upper
Saddle River, NJ: Prentice-Hall.

Worakham, P. 2012. Educational Research. Maha-Sarakham: Takkasila.

Yusawat, P. 1996. "Caring: Concept and Humanism of Nursing Theory.” Nursing 14(1):26-34.

\section{Bios}

Yaowaret Kanmali, Ph.D., Orthopedic Department, Kalasin Hospital; research fields: fundamental nursing, nursing administration, infectious control, nursing competency, educational and nursing evaluation, curriculum and instruction. Arun Suikraduang, Ph.D., assistant professor, Faculty of Research and Education Evaluation, Rajabhat Maha Sarakham University; research fields: educational evaluation, educational development, statistics and mathematics, and school physical education. 